\title{
Evaluationsbogen
}

\section{Multiples Myelom}

Angaben zur Person

Name, Vorname,Titel:

Straße, Hausnr.:

PLZ/Ort:

Ich bin Mitglied der Ärztekammer (bitte Namen der Kammer eintragen):

Anschrift: $\square$ privat $\square$ dienstlich

Jahr meiner Approbation:

Ich befinde mich in der Weiterbildung zum:

Ich habe eine abgeschlossene Weiterbildung in (bitte Fach eintragen):

Ich bin tätig als: $\square$ Assistenzarzt $\square$ Oberarzt $\square$ Chefarzt $\square$ niedergelassener Arzt $\square$ Sonstiges:

Ich bin DIMV-Abonnent: $\square$ ja $\square$ nein

Falls nein: ich habe den Fragebogen aus/von: $\square$ Thieme-connect $\square$ Kollegen $\square$ der Klinik $\square$ einer Bibliothek $\square$ Sonstiges

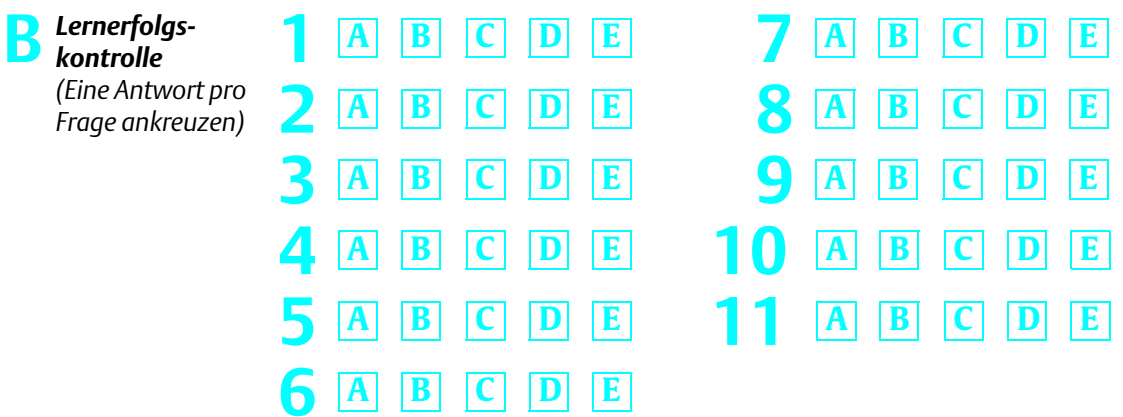

Erklärung Ich versichere, dass ich die Beantwortung der Fragen selbst und ohne fremde Hilfe durchgeführt habe

Ort/Datum: Unterschrift

Feld für CMEWertmarke

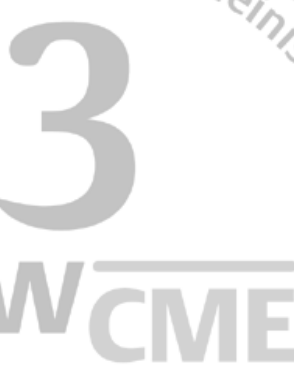
Bitte in dieses Feld die CME-Wertmarke kleben oder Ihre DMW Abonnement-Nummer eintragen: (siehe Adressaufkleber Ihrer DMW)

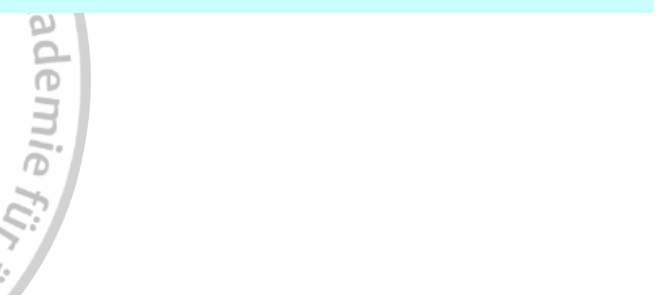

Zertifizierungsfeld (wird durch die DMW ausgefüllt)

\section{Ihr Ergebnis}

Sie haben von 11 Fragen richtig beantwortet. Im Durchschnitt wurden __ der Fragen richtig beantwortet. Sie haben $\square$ bestanden $\square$ nicht bestanden. $\square$ ungültig, weil:

Stuttgart, den Datum Stempel/Unterschrift 
Fragen zur Zertifizierung (bitte unbedingt ausfüllen bzw. ankreuzen, da

Evaluation sonst unvollständig!)

\section{Didaktisch-methodische Evaluation}

Multiples Myelom kommt in meiner ärztlichen Tätigkeit

$\square$ häufig vor

$\square$ regelmäßig vor

$\square$ selten vor

$\square$ gar nicht vor

2

Bezüglich Multiplem Myelom gab es für mich vor dem Studium dieses

Beitrages

$\square$ eine feste Gesamtstrategie

$\square$ noch offene Einzelprobleme:

$\square$ keine Strategie

3

Bezüglich Multiplem Myelom

$\square$ fühle ich mich nach dem Studium des Beitrages in meiner Strategie bestätigt

$\square$ habe ich meine Strategie verändert:

$\square$ habe ich erstmals eine einheitliche Strategie erarbeitet

$\square$ habe ich keine einheitliche Strategie ableiten können

4

Wurden aus der Sicht Ihrer täglichen Praxis heraus wichtige Aspekte des Themas

a) nicht erwähnt? $\square$ ja $\square$ nein

Wenn ja, welche:

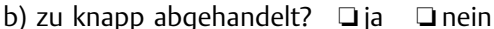

Wenn ja, welche:

c) überbewertet? $\square$ ja $\square$ nein

Wenn ja, welche:

Verständlichkeit des Beitrages

$\square$ Der Beitrag ist nur für Spezialisten verständlich

$\square$ Der Beitrag ist auch für Nicht-Spezialisten verständlich

Beantwortung der Frager

$\square$ Die Fragen lassen sich aus dem Studium des Beitrages allein beantworten

$\square$ Die Fragen lassen sich nur unter Zuhilfenahme zusätzlicher Literatur beantworten

Die Aussagen des Beitrages benötigen eine ausführlichere Darstellung

$\square$ zusätzlicher Daten

$\square$ von Befunden bildgebender Verfahren

$\square$ die Darstellung ist ausreichend

Wieviel Zeit haben Sie für das Lesen des Beitrages und die Bearbeitung des Quiz benötigt?

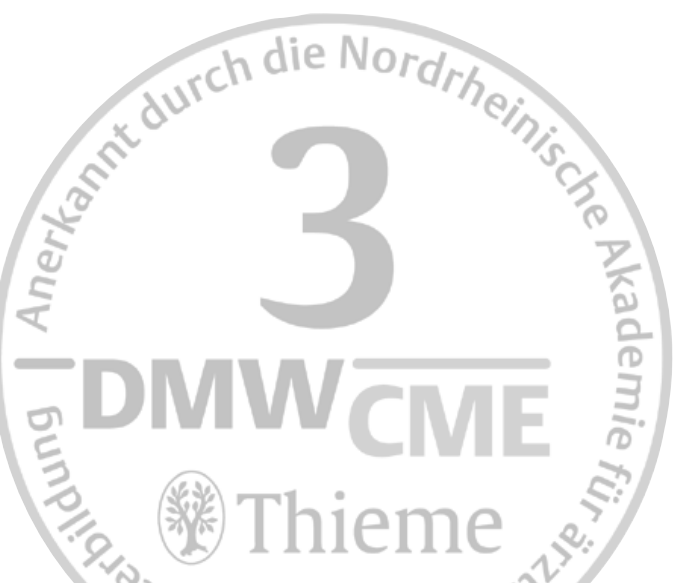

Für die Teilnahme auf dem Postweg senden Sie den vollständig ausgefüllten Evaluationsbogen mit aufgeklebter Wertmarke oder dem Eintrag Ihrer Abonnement-Nummer im Wertmarkenfeld $D$ und einen ausreichend frankierten und an Sie selbst adressierten Rückumschlag an:

Georg Thieme Verlag, DMW

Stichwort „CME“

Postfach 301120

70451 Stuttgart 